\title{
Serum concentrations of VEGF and bFGF in the course of propranolol therapy of infantile hemangioma in children: Are we closer to understand the mechanism of action of propranolol on hemangiomas?
}

\author{
Lidia Babiak-Choroszczak ${ }^{1, A-F}$, Kaja Giżewska-Kacprzakk ${ }^{1, A, C-F}$, Elżbieta Gawrych ${ }^{1, A, C-F}$, Katarzyna Fischer2,B,E,F, \\ Anna Walecka ${ }^{3, B, E, F}$, Lidia Puchalska-Niedbał ${ }^{4, B, E, F}$, Justyna Rajewska-Majchrzak ${ }^{1, A, E, F}$, Maciej Bagłaj ${ }^{5, D-F}$ \\ ${ }^{1}$ Department of Pediatric and Oncological Surgery, Pomeranian Medical University in Szczecin, Poland \\ ${ }^{2}$ Independent Laboratory of Rheumatic Diagnostics, Pomeranian Medical University in Szczecin, Poland \\ ${ }^{3}$ Department of Diagnostic Imaging and Interventional Radiology, Pomeranian Medical University in Szczecin, Poland \\ ${ }^{4}$ Department of Ophthalmology, Pomeranian Medical University in Szczecin, Poland \\ ${ }^{5}$ Department of Pediatric Surgery and Urology, Wroclaw Medical University, Poland \\ A - research concept and design; $\mathrm{B}$ - collection and/or assembly of data; $\mathrm{C}$ - data analysis and interpretation; \\ $D$ - writing the article; $E$ - critical revision of the article; $F$ - final approval of the article
}

Address for correspondence

Kaja Giżewska-Kacprzak

E-mail:k.gizewska@gmail.com

Funding sources

None declared

Conflict of interest

None declared

Received on November 7, 2017

Reviewed on December 15, 2017

Accepted on January 26, 2018

DOI

10.17219/acem/84800

Copyright

Copyright by Author(s)

This is an article distributed under the terms of the

Creative Commons Attribution Non-Commercial License

(http://creativecommons.org/licenses/by-nc-nd/4.0/)

\begin{abstract}
Background. Propranolol has become the treatment of choice for infantile hemangiomas (IH). Neither the pathogenesis of $\mathrm{IH}$ nor the mechanism of action of propranolol on them are well understood. Possible explanations include the inhibition of angiogenesis by decreasing vascular endothelial growth factor (VEGF) and basic fibroblast growth factor (bFGF), induction of vascular endothelial cell apoptosis and vasoconstriction.

Objectives. The aim of the study was to assess serum concentrations of VEGF and bFGF in the course of propranolol therapy of $\mathrm{IH}$ in children, and to assess their clinical implications.

Material and methods. The study included 51 children with $1 H$ treated with propranolol. The participants were assessed before, during and after the therapy with Hemangioma Activity Score (HAS), Doppler ultrasound (US) of the lesions, as well as VEGF and bFGF serum concentrations.
\end{abstract}

Results. All children showed clinical improvement measured in the HAS. A complete involution of the IH was reported in 32 (63\%) children at the time of decision of the gradual withdrawing of propranolol, and in 28 (61\%) patients at the end of the treatment (out of 46 patients present at the follow up after 1.5 months). Doppler US at the follow-up showed a complete disappearance of the blood flow in the lesion in 24 (52\%) children and its reduction in 12 (26\%) children. There was a significant decrease in VEGF and bFGF during and after treatment compared to pretreatment values. There was a correlation between the outcome of the Doppler US and changes in bFGF during and after treatment. Changes in VEGF during treatment did not correlate with changes in the Doppler US.

Conclusions. Serum concentrations of VEGF and bFGF decreased during the propranolol treatment of $I H$, which may indicate the effect of propranolol on both. However, the statistical analysis showed their low prognostic value as biochemical markers of propranolol treatment. Clinical evaluation combined with Doppler US is the most valuable method of monitoring the therapy.

Key words: infantile hemangioma, propranolol, vascular growth factor, vascular endothelial growth factor, basic fibroblast growth factor 


\section{Introduction}

Infantile hemangiomas $(\mathrm{IH})$ are the most common childhood soft tissue tumors - they affect about $10 \%$ of infants, including $20-30 \%$ of premature babies. ${ }^{1-4}$ The pathogenesis of hemangiomas remains unclear. ${ }^{2-5}$ The 3 most common theories, which do not exclude each other, are: a hypoxia theory, a theory about the small-vessel embolization by cells from the placenta, and a theory of angiogenesis and vasculogenesis increase by the activity of vascular endothelial growth factor (VEGF) and basic fibroblast growth factor (bFGF). ${ }^{3}$ The unique feature of $\mathrm{IH}$ is its natural development, which includes a phase of intensive growth (proliferation) lasting up to 18 months, and a phase of slow disappearance (involution). ${ }^{5}$ Unfortunately, both the beginning of the involution phase and its duration are unpredictable. Only in $40 \%$ of children the disappearance of the hemangioma leaves no trace or minimal residue, resulting in a good cosmetic effect. Most often, IH disappears, leaving telangiectasias, scars, excess skin, or the so-called fatty fibrous residue. ${ }^{5,6}$ Lesions of the periocular region or face, extensive in size, affecting inner organs or threatening life function, are particularly problematic. There is a high complication rate if no treatment is applied. ${ }^{5}$ As most of them are classified as inoperable, alternative treatment options have been sought. In 2008, Léauté-Labreze et al. introduced propranolol ( $\beta$-blocker) as an alternative treatment option for IH.7 Since then, propranolol has successfully become the treatment of choice. ${ }^{8,9}$ However, the mechanism of action of propranolol on $\mathrm{IH}$ is still not well understood.

According to Storch and Hoeger, the drug has 3 mechanisms of action that affect the lesion. ${ }^{4}$ The early effects (lightening of the IH and reduction of tension), seen in the first 3 days of treatment, are attributed to vasoconstriction as a result of reduced nitric oxide release. The intermediate effect is the inhibition of vascular tumor growth, most likely associated with a blockade of proangiogenic growth factors, such as VEGF, bFGF or metalloproteinase-2/9. The regression of the lesion classified as the long-term effect is caused by apoptosis of the proliferating endothelial cells.

The aim of the study was to assess serum concentrations of VEGF and bFGF in the course of propranolol therapy of $\mathrm{IH}$ in children as an attempt to assess their practical role as a biochemical marker of successful treatment.

\section{Material and methods}

The analysis included a group of 51 infants with IH, diagnosed and treated between 2011 and 2014.

The criteria for inclusion in the research project were IHs that had to be: nonoperative, extensive in size, ulcerative, resulting in an impairment of important vital functions, causing a significant cosmetic defect, or with lesions affecting internal organs.
The Bioethics Committee of the Pomeranian Medical University in Szczecin, Poland, approved the study proto$\mathrm{col}$, and reviewed and approved the consent forms. Written informed consent was obtained from the legal guardians of all of the study participants and recorded in the patient files.

\section{Methods}

After history taking of the occurrence and growth of the $\mathrm{IH}$ and coexistence of risk factors for $\mathrm{IH}$, clinical interventions were applied before, during and at the follow-up (1.5 months) after treatment, including:

- clinical examination with assessment of location, size, color and consistency, assessment in terms of Hemangioma Activity Score (HAS) (Table 1), and ophthalmic examination performed in lesions of the periocular region $^{1}$;

- photographic documentation;

- doppler US assessing the size and blood flow in the lesion with a ranking system applied: initial size of the IH ranked as 2, reduction during treatment which was less than $50 \%$ ranked as 1.5 , reduction greater than $50 \%$ ranked as 1 , and complete involution ranked as 0 ; the intensity of the blood flow was defined as increased $(++)$, moderate $(+)$ or absent $(-)$;

- serum concentrations of VEGF and bFGF before starting the treatment, at $6^{\text {th }}$ month of treatment and 1.5 months after treatment, carried out using the immunoenzyme method (ELISA);

- cardiological examination with electrocardiography, echocardiography and basic laboratory tests; blood

Table 1. Hemangioma Activity Score (HAS) ${ }^{1}$

\begin{tabular}{|c|c|}
\hline The assessed feature of the infantile hemangioma $(\mathrm{IH})$ & Points \\
\hline $\begin{array}{l}\text { Deep swelling: } \\
\text { tense } 1 \mathrm{H}(6) \\
\text { "neutral" } \mid \mathrm{H} \text { at } \mathrm{t}=0 \text { or less than } 50 \% \text { reduction at follow up } \\
\geq 50 \% \text { reduction at follow-up } \\
\text { no more swelling at follow-up }\end{array}$ & $\begin{array}{l}4 \\
6 \\
2 \\
0\end{array}$ \\
\hline Bright red/shining red $I H$ & 5 \\
\hline Bright red edge & 4 \\
\hline Matt red/reddish-purple $\mathrm{IH} /$ matt red edge & 3 \\
\hline Blue $\mathrm{IH}$ or blue shining through in deep $\mathrm{IH}$ & 2 \\
\hline Grey $I H$ & 1 \\
\hline Skin coloured after activity & 0 \\
\hline \multicolumn{2}{|l|}{ Total score } \\
\hline \multicolumn{2}{|l|}{ Number of items scored } \\
\hline \multicolumn{2}{|l|}{ Preliminary HAS = total score/number of items scored } \\
\hline $\begin{array}{l}\text { Ulcer score } \\
\text { ulcer } \leq 1 \mathrm{~cm}^{2} \\
\text { ulcer } 1-25 \mathrm{~cm}^{2} \\
\text { ulcer } \geq 25 \mathrm{~cm}^{2}\end{array}$ & $\begin{array}{c}0.5 \\
1 \\
2\end{array}$ \\
\hline HAS = preliminary HAS + ulcer score & \\
\hline
\end{tabular}

IH - infantile hemangioma. 
morphology, ionogram, serum glucose, aspartate aminotransferase (AST), and alanine aminotransferase (ALT) were performed for the safety of the therapy;

- oral propranolol introduced in 2 divided doses (at $8 \mathrm{AM}$ and $8 \mathrm{PM}$ ), according to the following protocol:

- $1^{\text {st }}$ day: $0.5 \mathrm{mg} / \mathrm{kg} /$ day;

- $2^{\text {nd }}$ day: $1 \mathrm{mg} / \mathrm{kg} /$ day;

- $3^{\text {rd }}$ day: $1.5 \mathrm{mg} / \mathrm{kg} /$ day;

- $4^{\text {th }}$ day: $2.0 \mathrm{mg} / \mathrm{kg} /$ day.

Treatment was introduced in hospital conditions for 4-5 days with monitoring of vital functions, including blood glucose levels, and then continued in outpatient settings.

\section{Statistical analysis}

All continuous variables were checked for the normality of the distributions by Kolmogorov-Smirnov test. These variables are described by means, medians, standard deviations (SD), quartiles, as well as minimum and maximum values. The statistical differences between the 2 groups were tested by Student's t-test and Mann-Whitney U test. Multiple variances (ANOVA), covariance (ANCOVA) or Kruskal-Wallis test were used for multiple groups. Variables in the same patient were tested with the Wilcoxon test or the t-test of dependent variables. Discrete variables were described by the amount and frequency. The Pearson's $\chi^{2}$ test was used to study the statistical relationships between discrete variables. For the study of the correlation between discontinuous and orderly variables (coded variables: 0/1), the Spearman's rank correlation coefficient was applied.

The results are described by the correlation coefficient (r) and the probability value (p). The statistically significant differences in all the tests performed were those with a probability value of $\mathrm{p}<0.05$. Significance level with p-value between 0.051 and 0.099 was designated as a trend at the limit of statistical significance.

Statistical analysis was carried out using Stata 11 statistical program (StataCorp LLC, College Station, USA; license No. 30110532736).

\section{Results}

The study group included 51 children, 36 (71\%) girls and 15 (29\%) boys. The age of patients at the time of introduction of propranolol ranged from 7 weeks to 21.8 months (mean 5.8 months). In the study, 39 (75\%) children - the largest group of patients - were 7 weeks to 6 months old (mean 3.6 months). In all cases, the evolutionary history was characteristic for $\mathrm{IH}$. The burden of risk factors included: prematurity of birth, low birth weight $(<2500 \mathrm{~g}$ in $17.6 \%$ of children) and children born from twin pregnancies (3 children, 5.8\%). Obstetric risk factors were reported by 5 mothers $(9.8 \%)$; other reported factors were (number of cases in brackets): invasive prenatal examination (1), cigarette smoking (2), alcohol use (1), and taking pharmaceuticals during pregnancy (28). There was a family history of $\mathrm{IH}$ in 11 children (21.5\%).

The hemangiomas were isolated in 39 (76.5\%) patients, while in the remaining $12(23.5 \%)$ cases multifocal lesions were found. A total number of 79 IHs were present in 51 patients. More than half of the patients had a lesion of the head. The localizations included (number of lesions in brackets): upper eyelid (9), lower eyelid (3), parotid gland (4), nose (7), upper and lower lip (7), other head areas (8), crotch area (7), upperlimb (8), lower limb (5), trunk (17), neck (1), oral cavity (2), and liver (1). Twelve children (23.5\%) had lesions complicated with ulceration.

The lesions that were less than $0.5 \times 0.5 \mathrm{~cm}$ in size or affected internal organs (liver) were excluded from evaluation in HAS. Before the treatment, HAS ranged from 3 to 6.5 points. The clinical improvement was expressed as a percentage; it presented the difference between the evaluation moment and pretreatment measurement. Significant clinical improvement (from $80 \%$ to 99\%) corresponded with almost complete disappearance of IH, with only slight skin discoloration, telangiectasia or excess skin. The result of $100 \%$ was an equivalent of a total disappearance of the hemangioma (Fig. 1). All children showed clinical improvement with a statistically significant reduction in HAS (Fig. 2). The best results were present at the
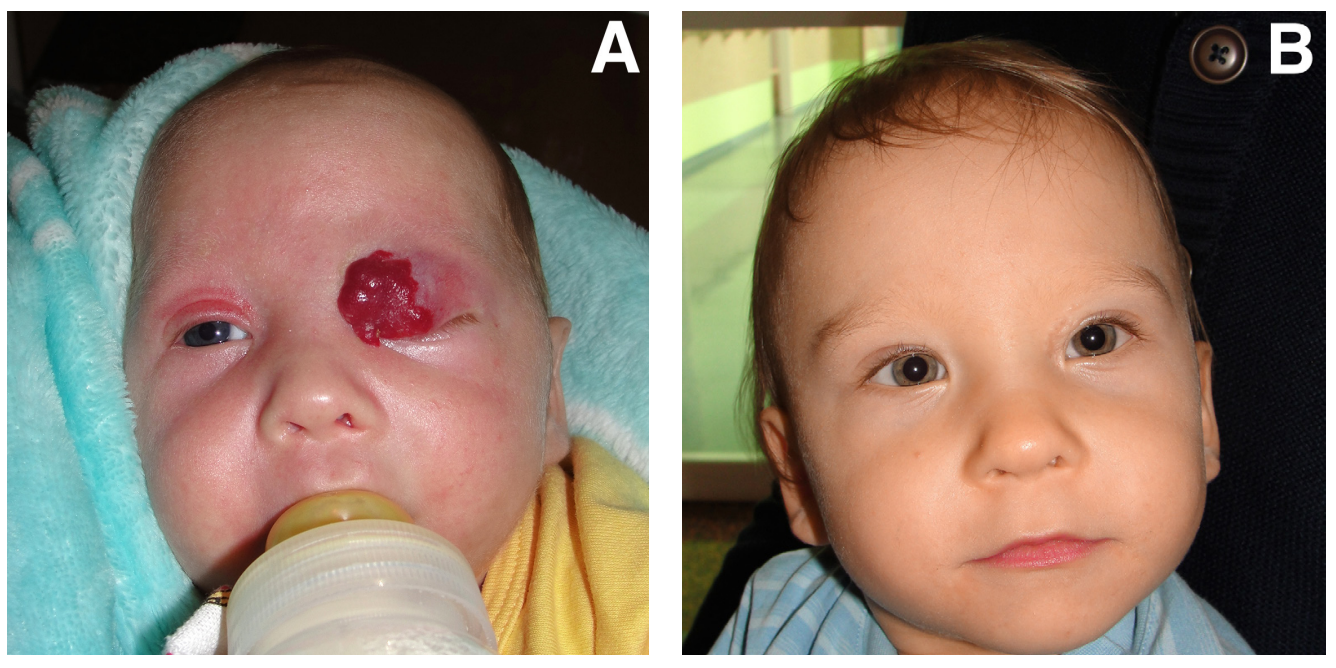

Fig. 1. Patient with hemangioma of the left upper eyelid causing severe ptosis

A - 2-month old child at admission (HAS: 4.3); $\mathrm{B}$ - after 12 months of propranolol treatment (HAS: 0); HAS - Hemangioma Activity Score. 


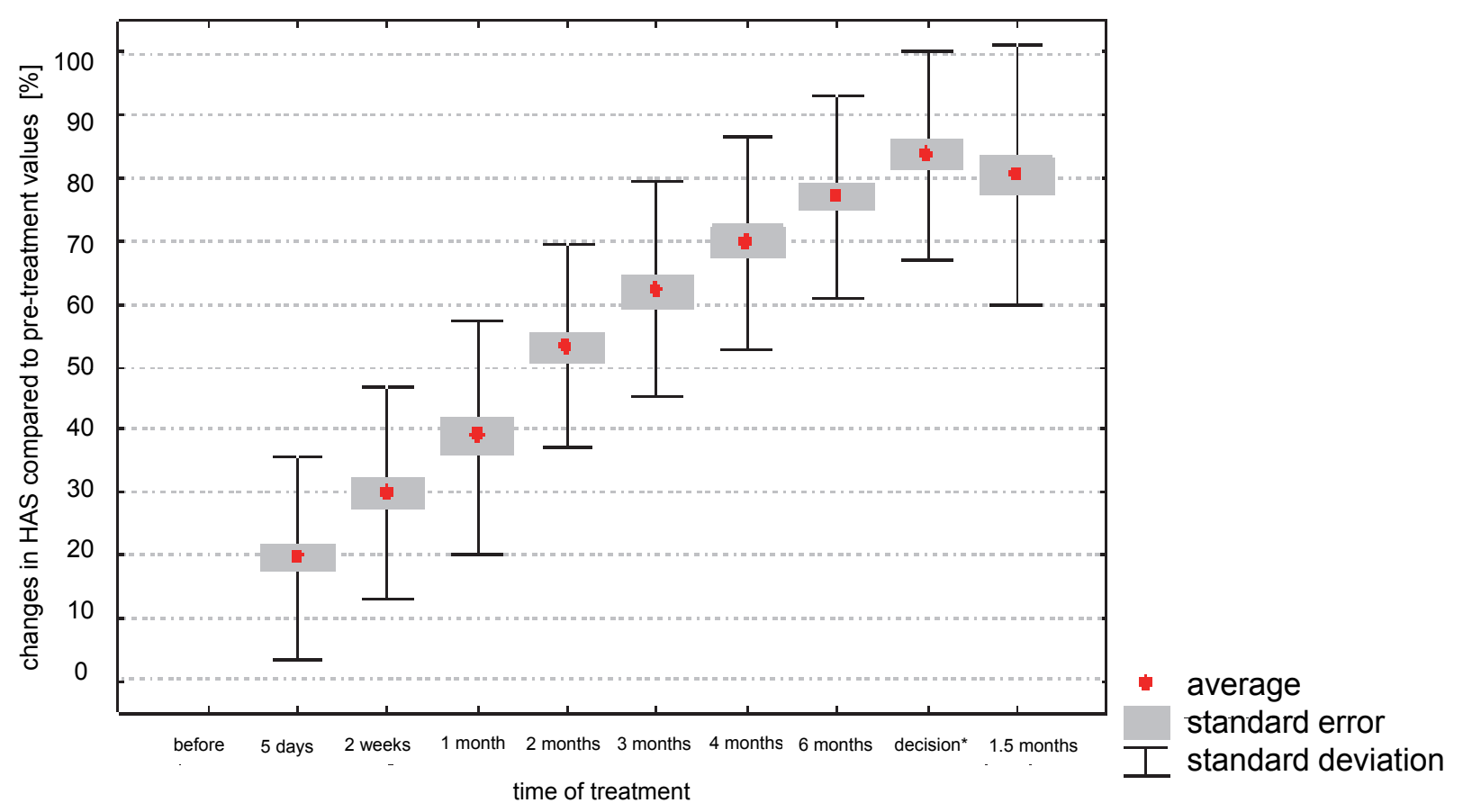

Fig. 2. Changes in Hemangioma Activity Score (HAS) throughout the propranolol treatment

* decision of gradual withdrawal of propranolol.

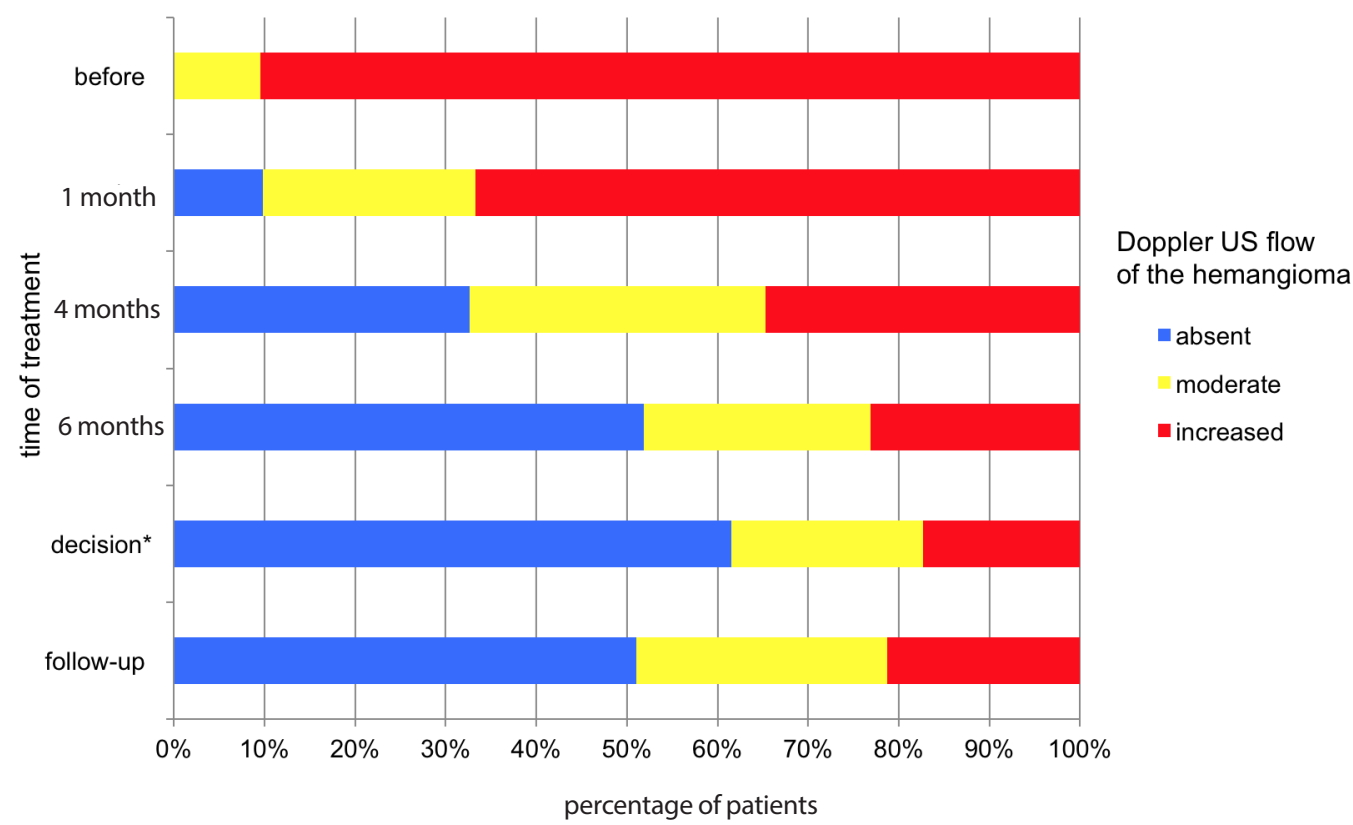

Fig. 3. Doppler US vascular flows in the hemangioma throughout the propranolol treatment

* decision of gradual withdrawal of propranolol.

Doppler US flow

\begin{abstract}
scular flows
withdraw
\end{abstract}


studies are shown in Fig. 3. There was a statistically significant decrease in vascular flow in the $\mathrm{IH}$, as compared to baseline $\mathrm{p}=0.00001$ and $\mathrm{p}=0.00688$ - before vs 1 month of treatment. A negative correlation was observed between the decrease in vascular flow and the length of therapy $(\mathrm{r}=-0.53 ; \mathrm{p}=0.00001)$. The highest correlation coefficient $(r=-0.76)$ was obtained between the study of the flow at the time of withdrawal of therapy and the study prior to initiation of the therapy. Significant reductions in the size of IH measured in Doppler US (at 0 to 2, corresponding to their percentage change from the baseline) were observed during therapy $(\mathrm{p}<0.015)$. At the end of treatment, the change in the size of the lesion (slight increase) was not statistically significant $(\mathrm{p}=0.8385)$. The highest percentage of lack of vascular flow (69\%) was observed in the youngest group of patients (Fig. 4).

Values of VEGF and bFGF were evaluated in 47 children. Values of serum VEGF levels before starting the treatment ranged from $40.862 \mathrm{pg} / \mathrm{mL}$ to $1151.928 \mathrm{pg} / \mathrm{mL}$, after 6 months of treatment - from $33.589 \mathrm{pg} / \mathrm{mL}$ to $1093.84 \mathrm{pg} / \mathrm{mL}$, after treatment ended - from $24.73 \mathrm{pg} / \mathrm{mL}$ to $722.074 \mathrm{pg} / \mathrm{mL}$. There was a statistically significant decrease in mean VEGF concentration during and after treatment compared to pretreatment values $(\mathrm{p}<0.05)$. There was a slight decrease in VEGF concentrations during and after treatment $(\mathrm{p}=0.11923)$. Mean values of VEGF did not correlate with number of lesions, location of $\mathrm{IH}$, age of the patients, or dose of propranolol.

The serum bFGF levels before starting the treatment ranged from $0 \mathrm{pg} / \mathrm{mL}$ to $30.125 \mathrm{pg} / \mathrm{mL}$, after 6 months of treatment - from $0 \mathrm{pg} / \mathrm{mL}$ to $40.92 \mathrm{pg} / \mathrm{mL}$, at the end of treatment - from $1.409 \mathrm{pg} / \mathrm{mL}$ to $25.472 \mathrm{pg} / \mathrm{mL}$. It was found that the mean pretreatment bFGF values differed significantly from the treatment and follow-up values ( $\mathrm{p}=0.0152$ and $\mathrm{p}=0.0139$, respectively). No statistically significant change in bFGF values was observed during and after treatment, with a slight increase in follow-up after treatment $(\mathrm{p}=0.1322)$. Mean values of bFGF did not correlate with the number of lesions or their location. At the border of statistical significance, lower values of bFGF were obtained in pediatric patients receiving the highest doses (1.86-2 mg/kg/day) of the drug during treatment ( $p=0.0558$ ). Furthermore, it was found that mean bFGF values were dependent on patient age both before and during treatment $(\mathrm{p}=0.007$ and $\mathrm{p}=0.0001$, respectively). The bFGF values were higher in the oldest group of children (18-21 months).

There was a statistically significant correlation between the outcome of the treatment and the changes in bFGF values during and after treatment. In the case of lack of flow in the Doppler US after treatment, a significant decrease in bFGF value was observed $(p=0.0206)$. In contrast, an increase in bFGF was noted in the case of persistently high blood flow in the post-treatment $(\mathrm{p}=0.0121)$ study (p-value was calculated with control of doses and age). There was no correlation between changes in VEGF values during and after treatment and vascular flows in Doppler US.

The target therapeutic dose was $2 \mathrm{mg} / \mathrm{kg} /$ day in 2 divided doses. In 6 children, the therapy was started at a lower dose (1.3-1.6 $\mathrm{mg} / \mathrm{kg} /$ day) due to younger age, low body weight and low serum glucose levels, and problems with normalization of the pulse during propranolol introduction. In 5 of these children, the dose was increased to the target dose after 1 month without any side effects.

Six children treated with full-dose therapy required a reduction in the therapeutic dose to $0.9-1.6 \mathrm{mg} / \mathrm{kg} /$ day due to adverse events (frequent cough and vomiting, sleep disorders, frequent respiratory infections, symptomatic hypoglycemia, reflux, and suspected asthma).

On average, the full dose was applied for 8.7 months and the total treatment time regarding the gradual withdrawal of the drug was 12 months. The drug was discontinued within 1.5-3 months, with gradual reduction of the dose.

\begin{tabular}{|l|l|l|l|}
\hline $\begin{array}{c}\text { Age at the introduction } \\
\text { of propranolol }\end{array}$ & $1-6$ months & 18-21 months \\
\hline $\begin{array}{c}\text { Doppler US flow of the } \\
\text { hemangioma }\end{array}$ & - absent =moderate - increased & - absent =moderate - increased & = absent = moderate - increased \\
\hline
\end{tabular}

Fig. 4. Relation between age of the child at introduction of propranolol and Doppler US examination at the time of decision of gradual withdrawal of treatment 


\section{Discussion}

In 2007, Chang et al. and Kleinman et al. published studies on the effect of tissue hypoxia on the development of $\mathrm{IH} .{ }^{10,11}$ According to those studies, hypoxia increases the expression of hypoxia-inducible factor 1-alpha (HIF1-alpha), which increases vascular endothelial growth factor A (VEGF-A) production by the non-oxidized endothelial cells. Both hypoxia and stromal cell-derived factor 1-alpha (SDF-1 alpha) increase the differentiation and proliferation of endothelial progenitor cells, leading to the development of hemangioma. ${ }^{10,11}$ Hypoxia is probably the strongest factor inducing angiogenesis and the formation of hemangioma. Multiple pregnancy, alcohol consumption, nicotinism, drug use during pregnancy, shortening of the pregnancy, low birth weight, and consequently poor general condition of the newborn are risk factors for IH and may be associated with increased tissue hypoxia. ${ }^{2}$

Elevated estrogens in the mother increase the risk of $\mathrm{IH}$ in a child. ${ }^{12}$ Estrogens stimulate endothelial cell division and increase the concentration of, i.a., metalloproteinase 9 and VEGF, as well as bFGF and nitric oxide (NO), directly and indirectly, and affect endothelial cell migration and angiogenesis. ${ }^{12}$ In the literature, the incidence of $\mathrm{IH}$ is higher in females, which is consistent with the dominance of girls in our study group. ${ }^{1}$

During proliferation, cells that build hemangioma (multipotent stem cells - CD133+, pericytes - $\mathrm{SMA}^{+}$, dendritic cells, mesenchymal cells, and immature endothelial cells $-\mathrm{CD}^{+} 1^{+}$) behave as if they were in the embryonic stage, multiplying much faster than the cells of the remaining tissues. Their intensive proliferation is linked to the activity of VEGF and bFGF. Proteases (collagenase type IV and urokinase) and adhesion molecules play role in the proliferation as well. ${ }^{2,3,5,13,14}$ Hu et al. demonstrated elevated serum VEGF levels in children with $\mathrm{IH}$ in the proliferative phase.${ }^{15}$ However, other authors have reported increased bFGF in both hemangioma tissue and urine in the proliferation phase, and normalization in the involuting phase. ${ }^{14,16,17}$

Research into the mechanism of action of propranolol on early hemangiomas is still ongoing. The clinical implications of finding a prognostic marker may include determining effective dosage and optimal age for treatment initiation and completion. Takahashi et al. analyzed 9 factors that can have an influence on angiogenesis. ${ }^{14}$ The study material consisted of biopsies at different stages of development (proliferation or involution). The research focused on the proangiogenic or antiangiogenic properties of the individual factors, and, consequently, determining their effect on the growth or disappearance of the IH. The presence of VEGF, type IV collagenase and proliferating cell nuclear antigen (PCNA) was only observed in the period of intense proliferation of choroidal lesions, whereas tissue metalloproteinase inhibitor (TIMP) was recorded only in the angiogenesis phase. The presence of bFGF was found both in the proliferative phase and in the involuting phase, without observing its presence after complete disappearance. ${ }^{14}$ These observations allowed the authors to assume that the selected factors may have a prognostic significance in determining the growth phase or involution. However, the invasive character of the surgical biopsy of lesions limits the use of this method.

Zhang et al. analyzed serum VEGF concentrations both in the proliferative phase and in the involuting phase. ${ }^{18}$ The results were compared with the values in healthy children. The authors demonstrated significantly higher VEGF values in patients with $\mathrm{IH}$ during the period of intensive proliferation compared to the values in healthy children. A similar dependence was observed by other authors, although they found remarkably low levels of this factor in the material taken directly from the hemangioma, both in the proliferative phase and in the involution. ${ }^{19,20}$

The proangiogenic properties of VEGF, as well as the effect of glucocorticoids on angiogenesis and vasculogenesis, have been reported in animal models. ${ }^{21}$ After the implantation of stem cells producing vascular endothelial growth factor A (VEGF-A) in mice and simultaneous administration of dexamethasone, other researchers observed a decrease in VEGF value and symptoms of atrophic decompression. These authors measured the angiogenic factors solely from angiogenic lesions. ${ }^{21}$ It is, therefore, possible that VEGF is responsible for the proliferation process. In the same way, the mechanism of action of propranolol can be explained. Multipotent stem cells from the hemangioma have vascular endothelial growth factor receptor 1 (VEGFR-1) receptors specific for VEGF-A. Linking them with VEGF-A protein induces the differentiation of these cells into vascular endothelial cells and subsequent vascular formation. ${ }^{22}$ According to Zhang et al., propranolol reduces VEGF expression in stem cells derived from hemangioma, which inhibits angiogenesis. ${ }^{23}$ The amount of VEGF produced by these cells decreases with the propranolol dose and is markedly reduced even at very low drug concentrations.

Our results confirm the correlation between high levels of VEGF and the phase of intensive proliferation. VEGF levels were also assessed in the study group during the proliferative phase, during which the possibility of correlation of VEGF values and patients' age was also analyzed. There was no statistically significant association between VEGF values and patient age. VEGF values in the course of treatment were significantly lower, which may indicate the efficacy of propranolol therapy. The observed lower VEGF values during the first 6 months and after treatment differed significantly from the values found before treatment. Similar results were obtained by Chinese researchers. ${ }^{24,25}$

The importance of bFGF in the proliferation and suppression of apoptosis of cells in the period of involution are to be emphasized. High concentrations are reported in the urine of patients with hemangiomas, whereas the decrease in urinary values is observed during treatment with interferon alpha $2 .{ }^{17,26}$ Therefore, the decrease of this 
factor should have a beneficial effect on the disappearance of the hemangioma. Przewratil et al. did not find a statistically significant difference in serum bFGF values in children with hemangiomas in the proliferative phase compared to the involuting phase. ${ }^{19}$ In addition, no difference was observed between healthy children compared to children with a vascular malformation. Subsequent studies by the same author showed statistically significant lower values of serum bFGF in the proliferative phase (median bFGF values of $19.445 \mathrm{pg} / \mathrm{mL}$ ) as compared to children with $\mathrm{IH}$ in the involuting phase $(32.034 \mathrm{pg} / \mathrm{mL})$. In addition, the author noted higher values of bFGF in the blood taken directly from hemangiomas than in the peripheral blood of the patients. ${ }^{27}$

In our study, low concentrations of bFGF were noted (mean $9.59 \mathrm{pg} / \mathrm{mL}$ ). There was also a statistically significant decrease in the value of this factor during the treatment (mean $6.45 \mathrm{pg} / \mathrm{mL}$ ). Evaluation of bFGF values before and after the treatment showed a statistically significant difference and may indicate the efficacy of propranolol in the treatment of early hemangiomas. In addition, bFGF level was found to be related to the age of the child - it was higher in older children. This relationship was not observed by other authors. ${ }^{27}$ The observed correlation between the decrease in bFGF concentrations after treatment and the disappearance of vascular flow in Doppler US has little prognostic value as it relates to changes that occurred after treatment was completed.

Although IHs undergo a natural involution, the generally accepted principle of "wait and see" is not always beneficial. Finn et al. divided the hemangiomas into those that involute by the age of 6 , and those whose disappearance lasted much longer. ${ }^{6}$ The early introduction of propranolol suppresses the stage of intense angiogenesis, reducing the possibility of cosmetic defects. However, in the absence of a full therapeutic effect, surgery or laser therapy is necessary. As a rule, it is considered that about $30 \%$ of hemangiomas disappear by 3 years of age and $50 \%$ by 5 years of age. ${ }^{5}$ According to Rajewska et al., only $17 \%$ of patients not treated and only monitored for 14.5 months showed the complete disappearance of the hemangioma. ${ }^{28}$ In the presented study group, there was a 3-fold increase in the rate of complete disappearance in 8.7 months of treatment, both in the clinical assessment and Doppler US. This indicates the important contribution of propranolol to the hastened process of involution.

Visible assessment of involution of IH does not always correspond with Doppler US of the lesion. Monitoring effects of propranolol should include both methods, especially at the time of the decision to cease therapy.

Propranolol is usually introduced in hospital settings, although there are reports of safe procedures in outpatient settings. ${ }^{29}$ The therapeutic dose should be in the range of $1-3 \mathrm{mg} / \mathrm{kg} /$ day, in 3 or 2 divided doses. ${ }^{30-32}$ In the study group, the treatment was started in the hospital for 4-5 days, starting from $0.5 \mathrm{mg} / \mathrm{kg} /$ day of propranolol until a maximum dose of $2 \mathrm{mg} / \mathrm{kg} /$ day in 2 divided doses, with final high effectiveness of such protocol.

The best efficacy of therapy is observed in children who started it before 1 year of age. ${ }^{30}$ However, Zvulunov et al. have reported good results of treatment introduced after 1 year of age. ${ }^{33}$ Our observations indicate that early initiation of therapy, even before the $6^{\text {th }}$ month of life, results in a faster disappearance of $\mathrm{IH}$, which is evident in both physical examination and Doppler US. However, all patients who received treatment after 1 year of age experienced significant clinical improvement, but no complete involution was observed.

The effect of propranolol is usually rapid, often seen in the early days of therapy. ${ }^{7,34-36}$ Visible changes between the $1^{\text {st }}$ and the $3^{\text {rd }}$ day of therapy are explained with vasospasms following the reduction of nitric oxide release. ${ }^{4}$ In the study group, a change of color or reduction of tension in the $1^{\text {st }}$ week of treatment was observed in $70 \%$ of patients, while at the end of the $1^{\text {st }}$ month it was noted in over $90 \%$ of children.

Probably, the observed lack of $\mathrm{IH}$ growth is an effect of the inhibition of bFGF and VEGF by acting on $\beta$-adrenergic receptors. An increase in the size of the hemangiomas during the treatment in 2 of our patients, confirmed by increased vascular perfusion in the Doppler US, could be caused by a decreased dose.

Complete involution is observed at different times from the introduction of the treatment. The treatment should last 6-8 months, but may be extended to $1-2$ years. ${ }^{7,8,34,35}$ The treatment should be continued until the end of the proliferative phase, to a minimum of 1 year of age, and in periocular hemangiomas until the defect (astigmatism) is corrected. ${ }^{35,37,38}$ Too early or rapid withdrawal may result in recurrence. ${ }^{29,36}$ In the study group, the mean duration of the treatment with the full therapeutic dose was 8.7 months. The best results were obtained by comparing the status between the beginning of the drug withdrawal and the pretreatment condition $(\mathrm{r}=-0.76)$. The duration of therapy was prolonged by gradual withdrawal, lasting 1-3 months, to minimize the recurrence risk and maintain a good therapeutic effect. Storch and Hoeger explain the absence of the recurrence by capillary vascular endothelial cell apoptosis induced by non-selective $\beta$-blockers. ${ }^{4}$ Kum and Khan have shown that only vascular endothelial cells undergo apoptosis, while stem cells - derived from arteries that are precursors of angiogenesis cells - do not. ${ }^{39}$ This may explain recurrence after the treatment, seen in about $20 \%$ of children. ${ }^{22}$

The limitations of this study include a small number of patients and lack of a control group. Nowadays, with the well-documented beneficial effects of propranolol therapy in $\mathrm{IH}$, it would be impossible, from an ethical point of view, to construct a methodology that would include a control group of children with $\mathrm{IH}$ not receiving any treatment. 


\section{Conclusions}

VEGF and bFGF values decrease during propranolol treatment of $\mathrm{IH}$, which may indicate the effect of propranolol on the change in both. However, the results of the statistical tests show a low prognostic value of VEGF and bFGF as possible biochemical markers for monitoring the treatment. Clinical evaluation combined with Doppler US is the most valuable method of monitoring the therapy.

\section{References}

1. Janmohamed SR, de Waard-van der Spek FB, Madern GC, et al. Scoring the proliferative activity of haemangioma of infancy: The Haemangioma Activity Score (HAS). Clin Exp Dermatol. 2011;36(7): 715-723.

2. Janmohamed SR, Madern GC, de Laat PCJ, et al. Educational paper: Pathogenesis of infantile haemangioma, an update 2014 (part I). Eur J Pediatr. 2015;174:97-103.

3. Lechańska J. Naczyniaki niemowlęce - od etiologii do postępowania terapeutycznego. DoveMed website. http://www.dovemed. $\mathrm{pl} /$ uploads/sfMediaBrowser//porady/naczyniaki-niemowl-ce.pdf. Accessed October 22, 2017.

4. Storch $\mathrm{CH}$, Hoeger PH. Propranolol for infantile haemangiomas: Insights into the molecular mechanisms of action. Br J Dermatol. 2010;163(2):269-274.

5. Wyrzykowski D, Bukowski M, Jaśkiewicz J. Guzy naczyniowe i wrodzone malformacje naczyniowe [in Polish]. Cancer Surg. 2009;1(1): 1-17. http://cancersurgery.pl/pdf/200901a02.pdf. Accessed October 22, 2017.

6. Finn MC, Glowacki J, Mulliken JB. Congenital vascular lesions: Clinical application of a new classification. J Pediatr Surg. 1983;18(6): 894-900.

7. Léauté-Labrèze $C$, Dumas de la Roque $E$, Hubiche T, et al. Propranolol for severe hemangiomas of infancy. NEngl J Med. 2008;358(24):26492651.

8. Janmohamed SR, Madern GC, de Laat PC, et al. Educational paper: Therapy of infantile haemangioma - history and current state (part II). Eur J Pediatr. 2015;174:259-266.

9. Drolet BA, Frommelt PC, Chamlin SL, et al. Initiation and use of propranolol for infantile hemangioma: Report of a consensus conference. Pediatrics. 2013;131(1):128-140.

10. Chang $\mathrm{E}$, Chang $\mathrm{E}$, Thangarajah $\mathrm{H}$, et al. Hypoxia, hormones, and endothelial progenitor cells in hemangioma. Lymphat Res Biol. 2007;5(4): 237-243.

11. Kleinman M, Greives M, Churgin S, et al. Hypoxia-induced mediators of stem/progenitor cell trafficking are increased in children with hemangioma. Arterioscler Thromb Vasc Biol. 2007;27:2664-2670.

12. Zhi-Yong S, Li Y, Cheng-Gang Y, et al. Possibilities and potential roles of estrogen in the pathogenesis of proliferation hemangiomas formation. Med Hypotheses. 2008;71:286-292.

13. Frieden IJ, Haggstrom AN, Drolet BA. Infantile hemangiomas: Current knowledge, future directions. Proceedings of a research workshop on infantile hemangiomas. April 7-9, 2005, Bethesda, Maryland, USA. Pediatr Dermatol. 2005;22(5):383-406.

14. Takahashi K, Mulliken J, Kozakewich H, et al. Cellular markers that distinguish the phases of hemangioma during infancy and childhood. J Clin Invest. 1994;93:2357-2364.

15. Hu Q, Lin X, Shang Q, et al. The determination and significance of VEGF in the serum of hemangioma patients. Arch Neurol. 2003;60:1613-1618.

16. Bielenberg DR, Bucana CD, Sanchez $R$, et al. Progressive growth of infantile cutaneous hemangiomas is directly correlated with hyperplasia and angiogenesis of adjacent epidermis and inversely correlated with expression of the endogenous angiogenesis inhibitor, IFN-beta. Int J Oncol. 1999;14:401-408.

17. Marler JJ, Fishman SJ, Kilroy SM, et al. Increased of urinary matrix metalloproteinases parallels the extent and activity of vascular anomalies. Pediatrics. 2005;116(1):38-45.
18. Zhang $\mathrm{L}$, Lin $\mathrm{X}$, Wang $\mathrm{W}$, et al. Circulating level of vascular growth factor in differentiating hemangioma from vascular malformation patients. Plast Reconstr Surg. 2005;116(1):200-205.

19. Przewratil P, Sitkiewicz A, Wyka K, et al. Serum levels of vascular endothelial growth factor and basic fibroblastic growth factor in children with hemangiomas and vascular malformations - preliminary report. Pediatr Dermatol. 2009;26(4):399-404.

20. Przewratil P, Sitkiewicz A, Andrzejewska E. Local serum levels of vascular endothelial growth factor in infantile hemangioma: Intriguing mechanism of endothelial growth. Cytokine. 2010;49(2):141-147.

21. Greenberger S, Boscolo E, Adini I, et al. Corticosteroid suppression of VEGF-A in infantile hemangioma-derived stem cells. NEngl J Med. 2010;362:1005-1013.

22. Kum JJ, Khan ZA. Mechanisms of propranolol action in infantile hemangioma. Dermatoendocrinol. 2015;6(1):e979699.

23. Zhang $L$, Mai HM, Zheng J, et al. Propranolol inhibits angiogenesis via down-regulating the expression of vascular endothelial growth factor in hemangioma-derived stem cell. Int J Clin Exp Pathol. 2013;7(1): 48-55.

24. Chen XD, Ma G, Huang Jl, et al. Serum-level changes of vascular endothelial growth factor in children with infantile hemangioma after oral propranolol therapy. Pediatr Dermatol. 2013;30(5):549-553.

25. Yuan WL, Jin ZL, Wei JJ, et al. Propranolol given orally for proliferating infantile haemangiomas: Analysis of efficacy and serological changes in vascular endothelial growth factor and endothelial nitric oxide synthase in 35 patients. Br J Oral Maxillofac Surg. 2013;51(7):656-661.

26. Chang E, Boyd A, Nelson CC, et al. Successful treatment of infantile hemangiomas with interferon-alpha 2b. J Pediatr Hematol Oncol. 1997;19:237-244.

27. Przewratil P, Sitkiewicz A, Andrzejewska E. Serum levels of basic fibroblastic growth factor (bFGF) in children with vascular anomalies: Another insight into endothelial growth. Clin Biochem. 2010;43(10-11): 863-867.

28. Rajewska J, Gawrych E, Fischer K, et al. Estimation of vascular endothelial growth factor and placental growth factor serum levels in infant with hemangioma and population of healthy infants. Ann Acad Med Stetin. 2012;58:5-10.

29. Haider KM, Plager DA, Neely DE, Eikenberry J, Haggstrom A. Outpatient treatment of periocular infantile hemangiomas with oral propranolol. J AAPOS. 2010;14(3):251-256.

30. Hoeger PH, Harper Jl, Baselga E, et al. Treatment of infantile haemangiomas: Recommendations of a European expert group. Eur J Pediatr. 2015;174(7):855-865.

31. Léauté-Labreze Ch, Hoeger P, Mazereeuw-Hautier J, et al. A randomized, controlled trial of oral propranolol in infantile hemangioma. N Engl J Med. 2015;372(8):735-746.

32. Andrzejewska E, Bacewicz L, Bagłaj M, et al. Zastosowanie propranololu w leczeniu naczyniaków krwionośnych wczesnodziecięcych - program wieloośrodkowej oceny skuteczności. Stand Med Probl Chir Dziec. 2011;1:19-22.

33. Zvulunov A, McCuaig C, Frieden IJ, et al. Oral propranolol therapy for infantile hemangiomas beyond the proliferation phase: A multicenter retrospective study. Pediatr Dermatol. 2011;28(2):94-98.

34. Snir M, Reich U, Siegel R, et al. Refractive and structural changes in infantile periocular capillary haemangioma treated with propranolol. Eye (Lond). 2011;25(12):1627-1634.

35. Thoumazet $F$, Léauté-Labrèze $C$, Colin J, et al. Efficacy of systemic propranolol for severe infantile haemangioma of the orbit and eyelid: A case study of eight patients. Br J Ophthalmol. 2012;96:370-374.

36. Claerhout I, Buijsrogge $M$, Delbeke $P$, et al. The use of propranolol in the treatment of periocular infantile haemangiomas: A review. Br J Ophthalmol. 2011;95(9):1199-1202.

37. Fabian ID, Ben-Zion I, Samuel C, et al. Reduction in astigmatism using propranolol as first-line therapy for periocular capillary hemangioma. Am J Ophthalmol. 2011;151(1):53-58.

38. Babiak-Choroszczak L, Giżewska-Kacprzak K, Puchalska-Niedbał L, et al. Propranolol as an effective treatment for inoperable periocular haemangiomas in children. Pomeranian J Life Sci. 2016;62:16-20.

39. Kum JJ, Khan ZA. Propranolol inhibits growth of hemangioma-initiating cells but does not induce apoptosis. Pediatr Res. 2014;75(3): 381-388. 